\title{
MOLECULAR DIVERSITY AND ANTIBIOTIC RESISTANCE GENE PROFILE OF SALMONELLA ENTERICA SEROVARS ISOLATED FROM HUMANS AND FOOD ANIMALS IN LAGOS, NIGERIA
}

\author{
Abraham Ajayi ${ }^{*}$, Stella IfeAnyi SMith ${ }^{2}$, Julien Coulibaly Kalpy ${ }^{3}$, \\ IBIDUNNI OREOLUWA BODE-SOJOBI ${ }^{4}$, YAO KOUAMÉ RENÉ ${ }^{3}$ and \\ ADEYEMI ISAAC ADELEYE ${ }^{1}$ \\ ${ }^{1}$ Department of Microbiology, University of Lagos, Akoka, Nigeria \\ ${ }^{2}$ Molecular Biology and Biotechnology Department, Nigerian Institute of Medical \\ Research, Lagos, Nigeria \\ ${ }^{3}$ Laboratoire de Bactériologie et Virologie Institut Pasteur de Côte d'Ivoire, \\ Centre Nationale de Référence de Salmonella, Paris, France \\ ${ }^{4}$ Department of Medical Microbiology, Lagos University Teaching Hospital, \\ Idi-Araba, Lagos, Nigeria
}

(Received: 17 April 2019; accepted: 23 May 2019)

Outbreaks of Salmonellosis remain a major public health problem globally. This study determined the diversity and antibiotic resistance gene profile of Salmonella enterica serovars isolated from humans and food animals. Using standard methods, Salmonella spp. were isolated from fecal samples, profiled for antimicrobial susceptibility and resistance genes. Seventy-one Salmonella isolates were recovered from both humans and food animals comprising cattle, sheep, and chicken. Forty-four serovars were identified, with dominant Salmonella Budapest (31.8\%). Rare serovars were present in chicken ( $S$. Alfort, $S$. Wichita, $S$. Linton, $S$. Ealing, and $S$. Ebrie) and humans ( $S$. Mowanjum, $S$. Huettwillen, $S$. Limete, and $S$. Chagoua). Sixty-eight percent of isolates were sensitive to all test antibiotics, while the highest rate of resistance was to nalidixic acid $(16.9 \% ; n=12)$, followed by ciprofloxacin $(11.3 \%$; $n=8)$ and tetracycline $(9.9 \% ; n=8)$. Five isolates $(7 \%)$ were multidrug-resistant and antimicrobial resistance genes coding resistance to tetracycline (tet $A)$, beta-lactam $\left(b l a_{T E M}\right.$ ), and quinolone/fluoroquinolone ( $q n r B$ and $q n r S$ ) were detected. Evolutionary analysis of gyrA gene sequences of human and food animal Salmonella isolates revealed variations but are evolutionarily interconnected. Isolates were grouped into four clades with $S$. Budapest isolate from cattle clustering with $S$. Budapest isolated from chicken, whereas $S$. Essen isolated from sheep and chicken was grouped into a clade. Diverse $S$. enterica serovars with high antibiotic resistance profile are

\footnotetext{
*Corresponding author; E-mail: ajayiabraham2013@gmail.com
} 
ubiquitous in food animals; hence, there is a need for surveillance and prudent use of antibiotics in human and veterinary medicine.

Keywords: antibiotic resistance genes, serotype, quinolone, diversity

\section{Introduction}

Salmonellosis continue to pose substantial health challenges in developed and developing countries [1]. Over 2,500 Salmonella enterica serovars have been identified and some of which are the etiology of salmonellosis that is presented mainly as enteric fever in cases caused by Salmonella Typhi or Paratyphi and gastroenteritis caused by other S. enterica serovars. While the former is most of the time severe and invasive, the latter tends to be self-limiting; however, it could be severe and systemic in infants, older people, and immunocompromised individuals [2-4]. Epidemiological surveillance overtime has revealed that outbreaks of salmonellosis in human are linked to ingestion of foods mainly of animal origin that are contaminated with Salmonella; thus, most Salmonella infections could be considered as zoonotic. However, host-specific serovars like $S$. Typhi transmission is often through the fecal-oral route and not considered to be zoonotic. Establishing the route of transmission is more or less difficult, since the transmission chain is complex $[2,5,6]$. Food animals (chicken, pork, cattle, sheep, and even fish) are a major reservoir of diverse serovars of $S$. enterica as has been documented in several reports [7-11]. This persistence of $S$. enterica in the intestinal tract of food animals creates a chronic or non-symptomatic carrier state that provides for continuous shedding of bacteria in feces, thereby serving as a reservoir for subsequent spread by contaminated meat, milk, eggs, and agricultural products cultivated on Salmonella-containing manure lands [12]. Not only food animals are sources of Salmonella infections, they also serve as a channel for the dissemination of multidrug-resistant (MDR) serovars, which in recent times has emerged as a threat to the effective treatment of infections. In a 2014 World Health Organization (WHO) report on resistance of selected bacteria of international concern to antibacterial drugs, non-typhoidal Salmonella (NTS) resistance to fluoroquinolones made the list with a total number of reports with data sets based on $\geq 30$ tested isolates to be as high as $75 \%$ [13]. Resistance of Salmonella spp. to most widely used classes of antibiotics spans from aminoglycosides, chloramphenicol, tetracycline, beta-lactams (including cephalosporin), quinolones, sulfonamide and trimethoprim to polymyxins [14-16]. In Nigeria, there has been reports of the isolation and antibiotic resistance profiling of Salmonella serovars isolated from humans, chicken, and pigs [17-19] but there is drought of information on studies that evaluates human and a broader range of food animals at once. 
Hence, this study explores the diversity and antibiotic resistance genes profile of Salmonella serovars isolated from humans and three major food animals in Lagos, Nigeria, a cosmopolitan city in West Africa.

\section{Materials and Methods}

Study design

The study is composed of humans and food animals (cattle, sheep, and chicken).

Group 1: This group comprised human subjects who were apparently healthy food handlers recruited based on the following criteria: (1) adults with $\geq 18$ years of age (both male and female) and (2) not on any form of antibiotic treatment. Sample size for human subject was defined as:

$$
n=\frac{Z^{2} p q}{d^{2}}
$$

where:

$Z \rightarrow$ Standard normal deviate $=1.96$

$p \rightarrow$ Prevalence $\cong 0.304$ according to Smith et al. [20]

$q \rightarrow 1-\mathrm{p}=1-0.304$

$d \rightarrow$ Tolerable margin of error $=0.05$

$n=n=\frac{(1.96)^{2} \times(0.304) \times(0.696)}{(0.5)^{2} 0.0025}=0.8128211$

$n=325.1$.

With a gazette $10 \%$ non-response rate $n=325+33=358$.

Group 2: This comprised apparently healthy food animals (cattle, sheep, and chicken) that were being processed for slaughter. One hundred and two fecal samples were collected from each animal type making the total sample size from animals to be 306 . Therefore, the total number of samples collected for both group was 664 .

\section{Sample collection}

Fecal samples were collected from humans, cattle, sheep, and chicken between June 2016 and March, 2017. Samples were collected from animals randomly selected each day of sample collection. Fecal samples were obtained after slaughter from viscera (intestine) in sterile specimen bottles appropriately 
labeled and transported in a thermobox at $4{ }^{\circ} \mathrm{C}$ to the laboratory immediately. Fecal samples were also collected from humans in sterile sample bottles and transported immediately to the laboratory under the same conditions earlier stated.

\section{Isolation and identification of isolates}

Five grams of each fecal sample were enriched in $25 \mathrm{ml}$ of selenite $\mathrm{F}$ broth (Oxoid, Basingstoke, UK) and incubated at $37^{\circ} \mathrm{C}$ for $18-24 \mathrm{~h}$. This was followed by plating onto Salmonella-Shigella agar (Oxoid) and incubated at $37^{\circ} \mathrm{C}$ for $24 \mathrm{~h}$. Presumptive colonies were further purified by subculturing on nutrient agar (Oxoid). Pure colonies were identified using biochemical tests including motility, indole, urease, mannitol, lysine decarboxylase, citrate, ortho-nitrophenyl$\beta$-galactoside, Kliger Iron Agar to determine $\mathrm{H}_{2} \mathrm{~S}$ and gas production, lactose and glucose fermentation, oxidase and catalase.

\section{Serotyping}

Serotyping of all biochemically confirmed Salmonella isolates was carried out at Centre Nationale de Référence de Salmonella, Laboratoire de Bactériologie et Virologie Institut Pasteur de Côte d'Ivoire according to White Kauffmann-Le Minor scheme [21]. Serotyping was carried out by slide agglutination test to characterize $\mathrm{O}$ and $\mathrm{H}$ antigens using commercially available antisera (Bio-Rad, F-92430 Marnes-La-Coquette, France).

\section{Antimicrobial susceptibility testing}

Antimicrobial susceptibility testing was performed using the disk diffusion method according to the European committee on antimicrobial susceptibility testing [22] guidelines. Salmonella isolates were inoculated into brain-heart infusion broth (Oxoid) and incubated at $37^{\circ} \mathrm{C}$ for $18 \mathrm{~h}$ after which they were subcultured on Mueller-Hinton agar (Hi-Media Laboratories Pvt. Ltd., India) at $37{ }^{\circ} \mathrm{C}$ for $24 \mathrm{~h}$. Two to three distinct colonies were emulsified in $5 \mathrm{ml}$ of sterile physiological saline and adjusted to $0.5 \mathrm{McFarland}$ standard and then a sterile swab stick was in applying bacteria suspension to the surface of Mueller-Hinton agar. Antibiotic disks were then applied comprising ampicillin $(10 \mu \mathrm{g})$, ciprofloxacin $(5 \mu \mathrm{g})$, tetracycline $(30 \mu \mathrm{g})$, minocycline $(30 \mu \mathrm{g})$, colistin $(50 \mu \mathrm{g})$, tobramycin $(10 \mu \mathrm{g})$, nalidixic acid $(30 \mu \mathrm{g})$, norfloxacin $(10 \mu \mathrm{g})$, imipenem $(10 \mu \mathrm{g})$, cephalotin $(30 \mu \mathrm{g})$, ceftazidime $(10 \mu \mathrm{g})$, gentamycin $(10 \mu \mathrm{g})$, aztreonam $(30 \mu \mathrm{g})$, ceftriaxone $(30 \mu \mathrm{g})$, 
cefuroxime $(30 \mu \mathrm{g})$, amikacin $(30 \mu \mathrm{g})$, chloramphenicol $(30 \mu \mathrm{g})$, cefotaxime $(5 \mu \mathrm{g})$, trimethoprim-sulfamethoxazole $(25 \mu \mathrm{g})$, amoxicillin +clavulanic acid $(30 \mu \mathrm{g})$, and cefepime $(30 \mu \mathrm{g})$ (Bio-Rad). The diameter of inhibition zone was measured using ADAGIO (Bio-Rad) and was interpreted as resistance (R), intermidiate (I), and sensitive (S). Escherichia coli ATCC 25922 was used as quality control organism.

\section{DNA extraction}

Phenol-chloroform-isoamyl alcohol method of DNA extraction according to Adi et al. [23] was adapted with modifications. Three to five colonies of bacterial isolates grown on Colombia Blood Agar overnight was emulsified in nuclease-free water to form a suspension. Cell suspension was refrigerated at $-20{ }^{\circ} \mathrm{C}$ for $15 \mathrm{~min}$ and then transferred to thermomixer held at $95{ }^{\circ} \mathrm{C}$ and incubated for $15 \mathrm{~min}$ at $500 \mathrm{rpm}$ and then centrifuged at 14,000 rpm for $10 \mathrm{~min}$, after which the supernatant containing the DNA was separated into a new sterile Eppendorf tube. To the supernatant, $500 \mu \mathrm{l}$ of phenol + chloroform + isoamyl (25:24:1) was added, vortexed, and then centrifuged at 13,000 rpm for $10 \mathrm{~min}$ at $4{ }^{\circ} \mathrm{C}$. Eight hundred microliter of supernatant was obtained to which $80 \mu \mathrm{l}$ of sodium acetate $+500 \mu \mathrm{l}$ of absolute $(100 \%)$ ethanol was added, vortexed gently, and stored at $-20{ }^{\circ} \mathrm{C}$ overnight. After centrifugation at $13,000 \mathrm{rpm}$ for $20 \mathrm{~min}$ at $4{ }^{\circ} \mathrm{C}$, supernatant was discarded while $1 \mathrm{ml}$ of ethanol $(70 \%)$ was added to the residue, vortexed gently, and then centrifuged at $13,000 \mathrm{rpm}$ for $10 \mathrm{~min}$ at $4{ }^{\circ} \mathrm{C}$; then, supernatant was discarded; later, the residue was maintained at $70{ }^{\circ} \mathrm{C}$ to allow the leftover ethanol to evaporate for 25-30 $\mathrm{min}$. Then, it was reconstituted with $60 \mu \mathrm{l}$ of Elu Buf (NucliSENS, BioMerieux, France). Purity of DNA was determined using a spectrophotometer and DNA was stored for further use at $-20{ }^{\circ} \mathrm{C}$.

Detection of antibiotic resistance genes by polymerase chain reaction (PCR)

Nine antibiotic resistance genes (tet $A, t e t B$, bla $_{\mathrm{TEM}}$, bla $_{\mathrm{SHV}}$, bla $_{\mathrm{CTX}-\mathrm{M}}, q n r A$, $q n r B$, qnrS, and $g y r A$ ) were assayed by PCR using primers listed in Table I. A $50-\mu \mathrm{l}$ PCR reaction was used that contained $28.8 \mu \mathrm{l}$ of nuclease-free water, $3.5 \mu \mathrm{MgCl}_{2}(25 \mathrm{mM}), 10 \mu \mathrm{l}$ of $5 \times$ PCR buffer, $1 \mu \mathrm{l}$ of dNTPs $(10 \mathrm{mM}), 0.75 \mu \mathrm{l}$ of each forward and reverse primers $(10 \mu \mathrm{M}), 0.2 \mu \mathrm{l}$ of one Taq DNA polymerase $(5,000 \mathrm{U} / \mathrm{ml})$ (New England Biolabs, Hertfordshire, UK), and $5 \mu 1$ DNA template. PCR was performed in a GeneAmp PCR system 9700 thermal cycler (AB Applied Biosystems, Singapore) with programming conditions determined empirically. 
Table I. Primers used in the detection of antibiotic resistance genes

\begin{tabular}{|c|c|c|c|}
\hline Primer & Sequence & $\begin{array}{l}\text { Amplicon } \\
\text { size }\end{array}$ & Reference \\
\hline$q n r A$ & F: 5'-GGATGCCAGTTTCGAGGA-3' & 502 & Cavaco et al. [24] \\
\hline$q n r A$ & R: 5'-TGCCAGGCACAGATCTTG-3' & & \\
\hline$q n r B$ & F: 5'-GGMATHGAAATTCGCCACTG-3' & 280 & Cattoir et al. [25] \\
\hline$q n r B$ & R: 5'-TTTGCYGYYCGCCAGTCGAA-3' & & \\
\hline$q n r S$ & F: 5'-TCGACGTGCTAACTTGCG-3' & 480 & Cavaco et al. [24] \\
\hline$q n r S$ & R: 5'-GATCTAAACCGTCGAGTTCGG-3' & & \\
\hline gyrA & F: 5'-TACCGTCATAGTTATCCACGA-3' & 300 & Wiuff et al. [26] \\
\hline gyrA & R: 5'-GTACTTTACGCCATGAACGT & & \\
\hline$b^{b l a} a_{\mathrm{TEM}}$ & F: 5'-GCGGAACCCCTATTTG-3' & 970 & Olesen et al. [27] \\
\hline$b l a_{\mathrm{TEM}}$ & R: 5'-ACCAATGCTTAATCAGTGAG-3' & & \\
\hline$b l a_{\mathrm{CTX}-\mathrm{M}}$ & F: 5'-ATGTGCAGYACCAGTAARGTKATGGC-3' & 605 & Hendriksen et al. [28] \\
\hline$b l a_{\mathrm{CTX}-\mathrm{M}}$ & R: 5'-TGGGTRAARTARGTSACCAGAAYSAGCGG-3' & & \\
\hline$b l a_{\mathrm{SHV}}$ & F: 5'-TTATCTCCCTGTTAGCCACC-3' & 796 & Arlet et al. [29] \\
\hline$b l a_{\mathrm{SHV}}$ & R: 5'-GATTTGCTGATTTCGCTCGG-3' & & \\
\hline tet $A$ & F: 5'-GTAATTCTGAGCACTGTCGC-3' & 988 & Waters et al. [30] \\
\hline tetA & R: 5'-CTGCCTGGACAACATTGCTT-3' & & \\
\hline $\operatorname{tet} B$ & F: 5'-CTC AGT ATT CCA AGC CTT TG-3' & 414 & Sengeløv et al. [31] \\
\hline tet $B$ & R: 5'-ACT CCC CTG AGC TTG AGG GG-3' & & \\
\hline
\end{tabular}

For $q n r A, q n r B, q n r S, g y r A, b l a_{\mathrm{SHV}}, b l a_{\mathrm{CTX}-\mathrm{M}}$, and tetB, 35 cycles of initial denaturation at $95{ }^{\circ} \mathrm{C}$ for $5 \mathrm{~min}$, denaturation at $95{ }^{\circ} \mathrm{C}$ for $30 \mathrm{~s}$, annealing at $60{ }^{\circ} \mathrm{C}$ for $30 \mathrm{~s}$, elongation at $72{ }^{\circ} \mathrm{C}$ for $1 \mathrm{~min}$, and final elongation at $72{ }^{\circ} \mathrm{C}$ for $10 \mathrm{~min}$ were used; whereas for $b l a_{\text {TEM }}$ and $t e t A$, PCR conditions were similar only with a different annealing temperature of $56^{\circ} \mathrm{C}$. The negative control was water, whereas positive controls include $S$. Typhimurium P5002212DT104 for gyrA, $S$. Virchou 58.67 Holland for bla $a_{\mathrm{CTX}}, S$. Bredeney TEM-104 (Gisele) for bla $a_{\mathrm{TEM}}$, S. Keurmassar DAK2 for bla ${ }_{\mathrm{SHV}}$, Enterobacter cloacae 03-577 for qnrA, Klebsiella pneumoniae KP15 for qnrB, Escherichia coli $\mathrm{pHC19}$ for qnrS, $E$. coli NCTC50078 for tetA, and E. coli CSH50:TN10 for tetB. PCR products were separated on a $1.5 \%$ agarose gel at $120 \mathrm{~V}$ and a 100-bp DNA ladder (New England Biolabs) was used as molecular weight maker.

\section{DNA sequencing}

PCR amplification products were sent to a commercial facility (Eurofins Genomics, France) for sequencing. Sequence results were analyzed and compared with sequences in the GenBank using BLAST (https://blast.ncbi.nlm.nih.gov/ Blast.cgi) and CARD (https://card.mcmaster.ca/analyze/blast). Phylogenetic analysis was performed using the MEGA 7.0 software [32]. 


\section{Statistical analysis}

Statistical analysis and graphics were performed using GraphPad Prism software 5.01 (La Jolla, CA, USA) and Microsoft Excel (Microsoft Cooperation, 2013 USA). Statistical significance of proportions was assessed using the $\chi^{2}$ test considering $p<0.05$ as significant.

\section{Results}

\section{Isolation and identification}

A total of 71 Salmonella isolates were recovered from 664 stool samples collected from humans, cattle, sheep, and chicken with a recovery rate of $10.7 \%$. Forty-eight percent of the isolates were obtained from chicken, whereas $22.5 \%$ was from sheep (Table II). Forty-four different serovars were identified with $S$. Budapest having the highest occurrence 31.8\% (14/44) followed by $S$. Essen $15.9 \%$ (7/44) with $S$. Paratyphi C having the least with $4.5 \%$ (2/44) (Table III).

\section{Antimicrobial susceptibility testing}

Altogether $68 \%$ of all Salmonella isolates $(n=48)$ were susceptible to all 21 test antibiotics. The highest rates of resistance was found to nalidixic acid, (12/71; $16.9 \%$ ) followed by ciprofloxacin $11.3 \%$, while resistance to tetracycline and minocycline was $9.9 \%$. Thirty-one percent $(n=22)$ of the entire isolates exhibited resistance to one or more of the test antibiotics, which was significant $(p<0.001)$ compared to the susceptible isolates. Seven percent $(n=5)$ of the antibiotic resistant isolates were MDR. Antibiotic resistance within population revealed

Table II. Distribution of the isolates from various sources and location

\begin{tabular}{|c|c|c|c|c|c|c|c|c|c|c|}
\hline \multirow[b]{2}{*}{ Site source } & \multicolumn{5}{|c|}{ Number of stool samples collected } & \multicolumn{5}{|c|}{$\begin{array}{c}\text { Number of Salmonella spp. isolated from } \\
\text { samples (\%) }\end{array}$} \\
\hline & $\mathrm{H}$ & $\mathrm{S}$ & $\mathrm{C}$ & $\mathrm{CH}$ & Total & $\mathrm{H}$ & $\mathrm{S}$ & $\mathrm{C}$ & $\mathrm{CH}$ & Total \\
\hline Lagos Island & 71 & 17 & 26 & 37 & 151 & 3 & 5 & 1 & 12 & 21 \\
\hline Mushin & 76 & 0 & 0 & 18 & 94 & 2 & 0 & 0 & 5 & 7 \\
\hline Alabarago & 55 & 22 & 68 & 7 & 152 & 2 & 2 & 9 & 6 & 19 \\
\hline Agege & 74 & 47 & 8 & 22 & 151 & 2 & 8 & 1 & 8 & 19 \\
\hline Ikeja & 49 & 0 & 0 & 0 & 49 & 1 & 0 & 0 & 0 & 1 \\
\hline Ikorodu & 33 & 16 & 0 & 18 & 67 & 0 & 1 & 0 & 3 & 4 \\
\hline Total & 358 & 102 & 102 & 102 & 664 & $10(14)$ & $16(23)$ & 11(15) & $34(48)$ & 71 \\
\hline
\end{tabular}

Note: Sample source - H: human; S: sheep; C: cattle; $\mathrm{CH}$ : chicken. 
Table III. The occurrence of Salmonella serovars identified

\begin{tabular}{|c|c|c|c|}
\hline CODE & Antigenic formula & Serotype & Frequency of isolation \\
\hline \multicolumn{4}{|c|}{ Isolates from chicken } \\
\hline $\mathrm{A} 11_{5} / 190$ & $(1,3,19: \mathrm{z}: \mathrm{I}, \mathrm{w})$ & S. Carno & 1 \\
\hline CF10/191 & $(1,4,12,[27]: \mathrm{g}, \mathrm{t:}$ _ $)$ & $S$. Budapest & 13 \\
\hline \multicolumn{4}{|l|}{ F2/194 } \\
\hline \multicolumn{4}{|l|}{$\mathrm{A} 15_{2} / 198$} \\
\hline \multicolumn{4}{|l|}{ E14/200 } \\
\hline \multicolumn{4}{|l|}{ CF13/201 } \\
\hline \multicolumn{4}{|l|}{$\mathrm{A} 6 / 202$} \\
\hline \multicolumn{4}{|l|}{$\mathrm{CF} 3 / 206$} \\
\hline \multicolumn{4}{|l|}{$\mathrm{F} 4 / 207$} \\
\hline \multicolumn{4}{|l|}{$\mathrm{Fe} / 213$} \\
\hline \multicolumn{4}{|l|}{ CF6/215 } \\
\hline \multicolumn{4}{|l|}{$\mathrm{CF} 9 / 216$} \\
\hline \multicolumn{4}{|l|}{$\mathrm{F} 5 / 219$} \\
\hline \multicolumn{4}{|l|}{$\mathrm{AF} 13 / 220$} \\
\hline B11y/196 & (35: gst:_) & S. Anecho & 3 \\
\hline \multicolumn{4}{|l|}{ AF5/199 } \\
\hline \multicolumn{4}{|l|}{ D10/204 } \\
\hline $\mathrm{E} 7 / 203$ & $(3\{10\}\{15\} 15,34: \mathrm{eh}: 1,5)$ & S. Muenster & 1 \\
\hline D8/209 & $(4,12:$ eh: 1,7$)$ & S. Kaapstad & 1 \\
\hline D6/205 & (35: gt: _) & S. Agodi & 2 \\
\hline \multicolumn{4}{|l|}{$\mathrm{E} 15 / 211$} \\
\hline $\mathrm{A} 2 / 212$ & $\left(8,20: Z_{4} Z_{23}: 1, w\right)$ & $S$. Dabou & 1 \\
\hline A11/214 & $\left(4,[5], 12: \mathrm{g}, \mathrm{z}_{51}: \mathrm{e}, \mathrm{n}, \mathrm{z}_{15}\right)$ & $S$. Tennyson & 1 \\
\hline $\mathrm{F}_{2} / 217$ & $(6,8: \mathrm{r}: 1, \mathrm{w})$ & S. Goldcoast & 1 \\
\hline $\mathrm{AF} 1 / 218$ & $\left(35: \mathrm{g}, \mathrm{m}, \mathrm{t}: \_\right)$ & S. Ebrie & 1 \\
\hline $\mathrm{AF} 6 / 221$ & $\left(4,12: \mathrm{g}, \mathrm{m}: \_\right)$ & $S$. Essen & 3 \\
\hline \multicolumn{4}{|l|}{$\mathrm{E} 8 / 224$} \\
\hline \multicolumn{4}{|l|}{ CF14/226 } \\
\hline $\mathrm{E} 6 / 222$ & $\left(4,[5], 12: 1, v: e, n, z_{15}\right)$ & $S$. Brandenburg & 1 \\
\hline $\mathrm{E} 4 / 225$ & $(3,10: f, g: e, n, x)$ & S. Alfort & 1 \\
\hline $\mathrm{F} 1 / 227$ & $(1,6,14,25: \mathrm{c}: 1, \mathrm{w})$ & S. Minna & 1 \\
\hline D3/193 & $(13,23: r: 1,6)$ & $S$. Linton & 1 \\
\hline D25/210 & $(1,13,23: \mathrm{d}: 1,6)$ & S. Wichita & 1 \\
\hline D14/223 & $\left(35: \mathrm{g}, \mathrm{m}, \mathrm{s}: \_\right)$ & $S$. Ealing & 1 \\
\hline Total & & & 34 \\
\hline \multicolumn{4}{|c|}{ Isolates from sheep } \\
\hline $\mathrm{S} 59 / 230$ & $(6,7,14: \mathrm{d}: 1, \mathrm{w})$ & S. Livingstone & 1 \\
\hline $\mathrm{S} 63 \mathrm{~B} / 231$ & $(6,7: \mathrm{d}: 1,6)$ & S. Kivu & 1 \\
\hline $\mathrm{S} 43 / 232$ & $(17: c: 1,5)$ & $S$. Berlin & 1 \\
\hline S57/233 & $(4,12: \mathrm{g}, \mathrm{m}:-)$ & $S$. Essen & 4 \\
\hline \multicolumn{4}{|l|}{$\mathrm{S} 38 \mathrm{~B} / 235$} \\
\hline \multicolumn{4}{|l|}{ S56/236 } \\
\hline \multicolumn{4}{|l|}{ S81/247 } \\
\hline $\mathrm{S} 36 \mathrm{C} / 237$ & $(17: b: 1,5)$ & S. Dahra & 2 \\
\hline \multicolumn{4}{|l|}{ S36/241 } \\
\hline S37/240 & $(4,12: I, w: 1,5)$ & S. Mono & 1 \\
\hline
\end{tabular}


Table III. The occurrence of Salmonella serovars identified (Continued)

\begin{tabular}{|c|c|c|c|}
\hline CODE & Antigenic formula & Serotype & Frequency of isolation \\
\hline S61/239 & $(1,4,12: z 10: I, w)$ & S. Mura & 1 \\
\hline S28/242 & $(8,20: z 10: e, n, z 15)$ & S. Chomedey & 1 \\
\hline S38/243 & $(8,20: \mathrm{d}: 1,5)$ & S. Yovokome & 1 \\
\hline $\mathrm{S} 43 / 244$ & $(16: \mathrm{d}: 1,5)$ & S. Sculcoates & 1 \\
\hline $\mathrm{S} 51 / 246$ & $(1,4,12[27]: \mathrm{b}: 1, \mathrm{w})$ & $S$. Wien & 1 \\
\hline S76/234 & $(3\{10\}\{15\}\{15,34\}: \mathrm{y}: 1,5)$ & S. Orion & 1 \\
\hline Total & & & 16 \\
\hline \multicolumn{4}{|c|}{ Isolates from cattle } \\
\hline $\mathrm{CO} 18 / 249$ & $(3,10: \mathrm{d}: 1,7)$ & S. Onireke & 1 \\
\hline $\mathrm{CO} 67 / 248$ & $\left(6,7: \mathrm{z}_{4} \mathrm{Z}_{24}:{ }_{-}\right)$ & S. Somone & 1 \\
\hline $\mathrm{CO} 20 / 251$ & $(13,23: z: 1,6)$ & $S$. Farmsen & 4 \\
\hline \multicolumn{4}{|l|}{$\mathrm{CO} 15 / 252$} \\
\hline \multicolumn{4}{|l|}{$\mathrm{CO} 26 / 257$} \\
\hline \multicolumn{4}{|l|}{$\mathrm{CO} 38 / 255$} \\
\hline $\mathrm{CO} 101 / 250$ & $\left(28: \mathrm{z}_{4} \mathrm{z}_{24}:-\right)$ & $S$. Ketheabarny & 1 \\
\hline $\mathrm{CO} 19 / 253$ & $\left(1,4,12[27]: \mathrm{gt}: \_\right)$ & $S$. Budapest & 1 \\
\hline $\mathrm{CO} 37 / 254$ & $\left(43,: \mathrm{g}, \mathrm{z}_{62}: \mathrm{enx}\right)$ & II & 1 \\
\hline $\mathrm{CO} 50 / 256$ & $\left(1,4,12,27: \mathrm{lz}_{13} \mathrm{z}_{28}: \mathrm{e}, \mathrm{n}, \mathrm{z}_{15}\right)$ & $S$. Vom & 1 \\
\hline $\mathrm{CO} 12 / 258$ & $\left(1,4,[5], 12:\right.$ eh: $^{\left.-e n z_{15}\right)}$ & S. Sandiego & 1 \\
\hline Total & & & 11 \\
\hline \multicolumn{4}{|c|}{ Isolates from human } \\
\hline H132/266 & $(1,4,12,[27]: b: 1,5)$ & S. Limete & 1 \\
\hline $\mathrm{H} 44 / 267$ & $\left(9,12: z_{10}: 1,5\right)$ & S. Portland & 1 \\
\hline $\mathrm{H} 45 / 268$ & $(1,4,12: a: I, w)$ & $S$. Huettwillen & 1 \\
\hline $\mathrm{H} 63 / 269$ & $(6,8: z: 1,5)$ & $S$. Mowanjum & 1 \\
\hline HL8/263 & $(6,7[\mathrm{vi}]: \mathrm{c}: 1,5)$ & S. Paratyphi C & 2 \\
\hline \multicolumn{4}{|l|}{$\mathrm{H} 418 / 274$} \\
\hline $\mathrm{H} 363 / 271$ & $(1,4,12,27: \mathrm{i}: 1,2)$ & S. Tyhpimurium & 1 \\
\hline $\mathrm{H} 209 / 272$ & $(6,8: \mathrm{i}: 1,5)$ & $S$. Takoradi & 1 \\
\hline H183/273 & $(1,4[5], 12: b: 1,2)$ & S. Paratyphi B & 1 \\
\hline H117/275 & $(1,13,23: a: 1,5)$ & S. Chagoua & 1 \\
\hline Total & & & 10 \\
\hline
\end{tabular}

that $43.8 \%(n=7 / 16)$ of isolates from sheep showed resistance to one or more antibiotics closely followed by isolates from humans with $40 \%(4 / 10)$ resistance. Percentage of antibiotic resistance of Salmonella isolates from chicken was $29.4 \%$ (10/34; Figure 1).

Detection of resistance genes by PCR

From PCR analysis, Salmonella isolates that displayed phenotypic resistance to antibiotics were positive for some antibiotic resistance genes assayed 


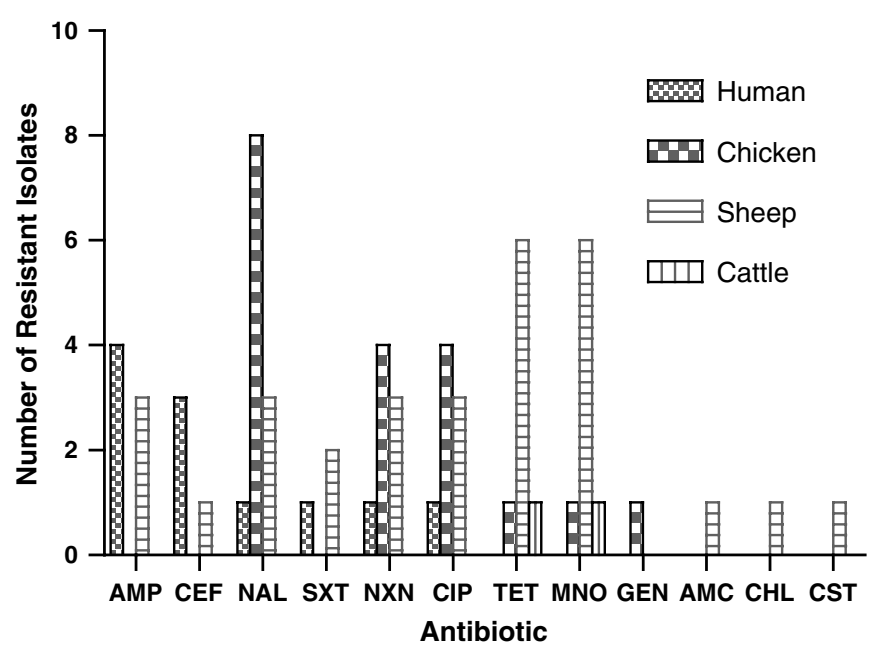

Figure 1. Distribution of resistance to antibiotics among Salmonella isolates from human, chicken, sheep and cattle. AMP: ampicillin; CEF: cephalotin; NAL: nalidixic acid; SXT: trimethoprim/ sufamethoxazole; NXN: norfloxacine; CIP: ciprofloxacin; TET: tetracycline; MNO: minocycline;

GEN: gentamycin

(Table IV). $q n r B$ gene was detected in $10(45.4 \%)$ of the isolates and $q n r S$ was detected in 1 isolate (Figures 2 and 3). bla $a_{\mathrm{CTX}}, b l a_{\mathrm{SHV}}$, and $q n r A$ were not detected in any of the isolates; however, $22.7 \%(5 / 22)$ was positive for $b l a_{\mathrm{TEM}}$ tet $A$ was also detected in $18.1 \%(4 / 22)$ of the isolates. The gyrA sequences of 12 isolates (GenBank accession numbers: MG593259-MG593270) were grouped into four clades with $S$. Typhimurium largely diverged. $S$. Budapest isolated from cattle and $S$. Budapest isolated from chicken were close, whereas $S$. Essen from sheep and chicken was grouped together in a clade, indicating evolutionary relatedness. Some isolates were grouped alongside $S$. Typhimurium (accession numbers: X78977 and EU512997) from GenBank (Figure 4).

\section{Discussion}

Diversity and gene variation among antibiotic-resistant $S$. enterica serovars of food animal sources continues to expand. Of the 71 Salmonella isolates from human, cattle, sheep, and chicken, 44 serovars were obtained with isolates from chicken accounting for 17 of these serovars. This is not surprising as poultry has been known to be a major reservoir and vehicle of transmission of $S$. serovars to humans [33]. S. Budapest had the highest rate of occurrence in poultry from different locations sampled. Although this serovar has not been reported in any 
Table IV. Antimicrobial resistance phenotype, and genes of Salmonella serovars isolated from humans, chicken, sheep, and cattle

\begin{tabular}{|c|c|c|c|c|}
\hline Code & Origin & Phenotype & Genes & Serotype \\
\hline $\mathrm{F} 5 / 219$ & Chicken & NAL, NXN, and CIP & $g y r A$ and $q n r B$ & $S$. Budapest \\
\hline CF3/206 & Chicken & NAL & gyr $A$ and $q n r B$ & S. Budapest \\
\hline $\mathrm{Fe} / 213$ & Chicken & NAL, NXN, and CIP & gyr $A$ and $q n r B$ & $S$. Budapest \\
\hline $\mathrm{A} 15_{2} / 198$ & Chicken & NAL & $q n r B$ & $S$. Budapest \\
\hline A115/190 & Chicken & NAL & gyrA & S. Carno \\
\hline D6/205 & Chicken & NAL, NXN, and CIP & $g y r A$ and $q n r B$ & $S$. Agodi \\
\hline $\mathrm{A} 11 / 214$ & Chicken & NAL, & gyrA and $q n r B$ & $S$. Tennyson \\
\hline $\mathrm{AF} 6 / 221$ & Chicken & NAL, NXN, and CIP & gyr $A$ and $q n r B$ & $S$. Essen \\
\hline A2/212 & Chicken & TET and MNO & $q n r B, q n r S$, and TetA & $S$. Dabou \\
\hline E14/200 & Chicken & GMI & - & $S$. Budapest \\
\hline $\mathrm{CO} 19 / 253$ & Cattle & TET and MNO & TetA & $S$. Budapest \\
\hline H117/275 & Human & AM, NAL, SXT, NXN, and CIP & gyrA and TetA & S. Chagoua \\
\hline H63/269 & Human & $\mathrm{AM}$ and $\mathrm{CEF}$ & - & S. Mowanjum \\
\hline $\mathrm{H} 44 / 267$ & Human & $\mathrm{AM}$ and $\mathrm{CEF}$ & - & $S$. Portland \\
\hline H363/271 & Human & $\mathrm{AM}$ and $\mathrm{CEF}$ & - & $S$. Typhimurium \\
\hline S57/233 & Sheep & $\mathrm{AM}$ and TET & $b l a_{\mathrm{TEM}}$ and $T e t A$ & $S$. Essen \\
\hline $\mathrm{S} 38 \mathrm{~B} / 235$ & Sheep & AM, TET, and SXT & $b^{b l a}{ }_{\mathrm{TEM}}$ & $S$. Essen \\
\hline S56/236 & Sheep & NAL, NXN, and CIP & gyrA and $q n r B$ & $S$. Essen \\
\hline $\mathrm{S} 81 / 247$ & Sheep & MNO and TET & $b l a_{\mathrm{TEM}}$ & $S$. Essen \\
\hline S61/239 & Sheep & NAL, NXN, and CIP & gyrA & $S$. Mura \\
\hline $\mathrm{S} 28 / 242$ & Sheep & NAL, TET, SXT, NXN, and CIP & $q n r B$ and $b l a_{\mathrm{TEM}}$ & S. Chomedey \\
\hline S51/246 & Sheep & MNO and TET & $b^{b l a}{ }_{\mathrm{TEM}}$ & $S$. Wien \\
\hline
\end{tabular}

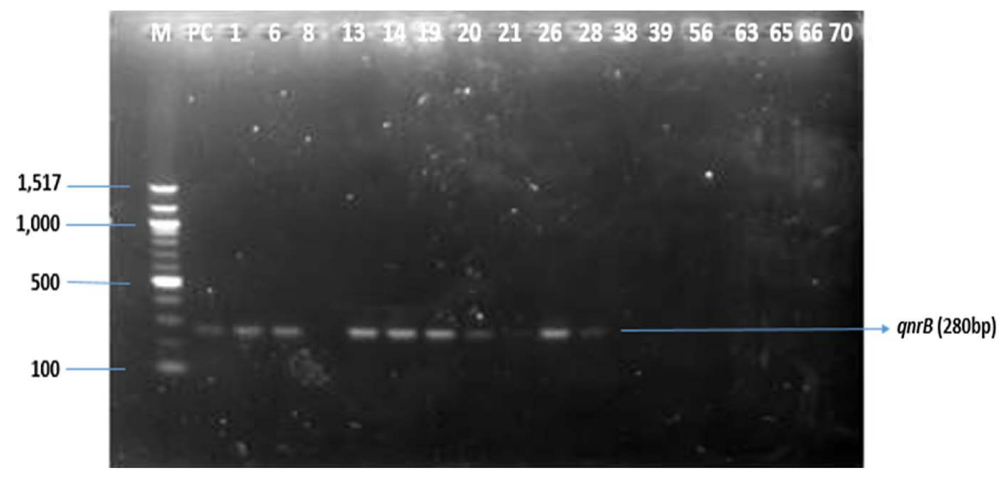

Figure 2. Agarose gel image of PCR products showing positive bands for $q n r B$. Lane 1- M: 100-bp DNA marker, lane 2 - PC: positive control Klebsiella pneumonia KP15, lane 19 - NC: negative control, 1- $S$. Carno, 6, 8, 14, 20, 26- $S$. Budapest, 13- S. Agodi, 19- S. Dabou, 21-S. Tennyson, and 28- $S$. Essen 


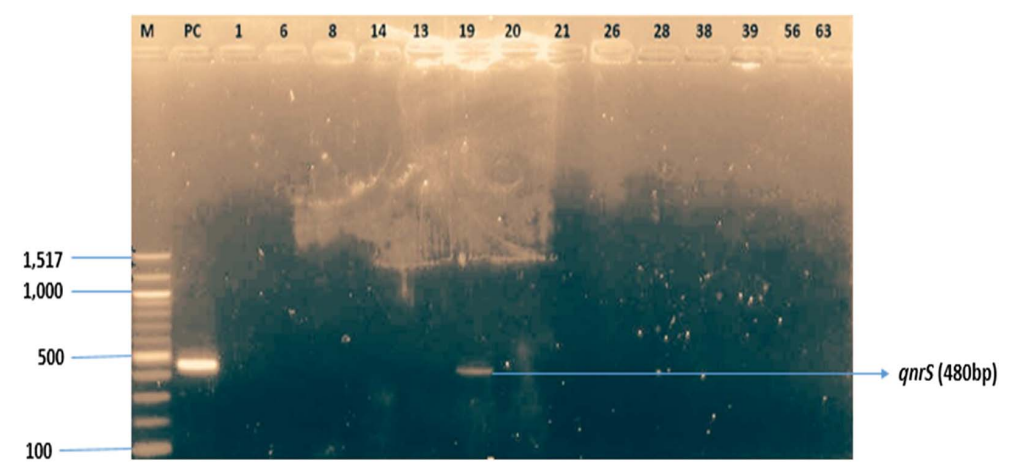

Figure 3. Agarose gel image of PCR products showing positive bands for qnrS. Lane $1-\mathrm{M}$ : 100-bp DNA marker, lane 2 - PC: positive control Escherichia coli pHC19, lane 16 - NC: negative control, 19- $S$. Dabou

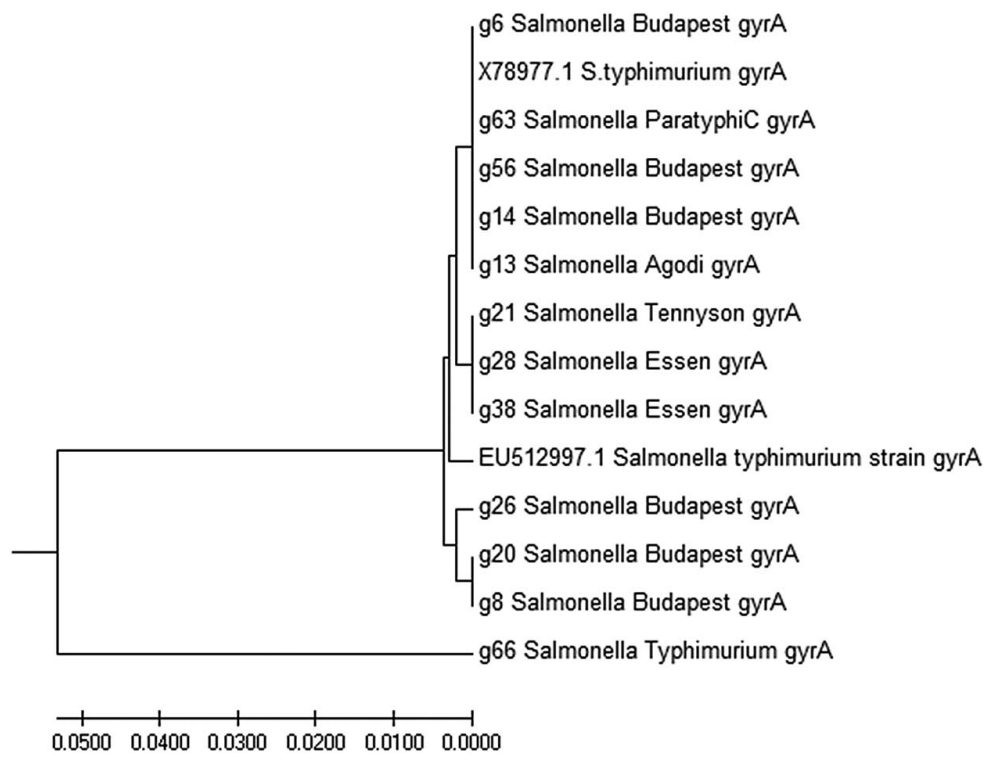

Figure 4. gyrA phylogenetic tree constructed based on an alignment of gyrA sequences of 12 isolates from human, chicken, cattle, and sheep with gyrA gene of Salmonella Typhimurium (EU512997 and X78977) from GenBank

human outbreak in Nigeria, a 2016 Salmonella annual report of the Centers for Disease Control and Prevention USA reported $S$. Budapest isolated from at least one patient with enteric fever in the USA between 2003 and 2013 [34]. NTS serovars accounted for majority of $S$. serovars from all three food animals 
(cattle, sheep, and chicken). NTS serovars have a vast host range including ruminants and birds with their products (eggs, meat, and milk) acting as vehicle for the transmission of Salmonella infections to humans and have been implicated in bacterial bloodstream infections in children and adults in sub-Saharan Africa [35-37]. Rare serovars were present in chicken, which included $S$. Alfort, $S$. Wichita, $S$. Linton, $S$. Ealing, and $S$. Ebrie. In a similar study, Smith et al. [6] reported the occurrence of rare serovars including $S$. Amoutive, $S$. Ealing, $S$. Urbana, $S$. Bargny, $S$. Drac, and $S$. Nyborg in beef, chicken, goat, and pork sold in different markets in Lagos Nigeria. Food animals remain a major source of diverse serovars of Salmonella. This study reports the first isolation of rare serovars $S$. Mowanjum, $S$. Huettwillen, $S$. Limete, and $S$. Chagoua from apparently healthy humans in Nigeria. Although these serovars have been isolated from animals, animal products, and animal feeds in Denmark and Thailand, respectively $[38,39]$. This finding is of public health relevance because these individuals who are food handlers are likely to disseminate the bacteria, since Salmonella has the tendency of persisting in macrophages and other immune cells coupled with chronic carrier status, which entails excreting the bacteria for some time that may be the case in this study [40]. No same serovar was recovered from human and animal sources, which indicates the difficulty in establishing the route of transmission of Salmonella serovars within the food chain. However, one isolate of $S$. Budapest was isolated from cattle and isolates of $S$. Essen were recovered from both chicken and sheep. Salmonella serovars displayed varied antibiotic susceptibility pattern with $16.9 \%$ resistance to nalidixic acid and $11.3 \%$ resistance to ciprofloxacin and norfloxacin. Most of these resistances to tested quinolone and fluoroquinolones were observed in isolates from chicken and sheep, which corroborates the findings of Raufu et al. [41] who reported a high-level resistance of Salmonella isolates of poultry origin to ciprofloxacin and nalidixic acid in the northern-eastern region of Nigeria. Zhu et al. [42] also reported a very high rate of resistance to nalidixic acid (99.5\%) and ciprofloxacin (43\%) in Salmonella isolates of poultry origin in China. This indicates a high use of quinolones in both human and veterinary medicine. Some isolates phenotypically exhibited resistance to some of the test antibiotics with no concomitant detection of resistance genes responsible for such resistance. This was observed in both human and animal isolates, for example $S$. Mowanjum, $S$. Portland, and $S$. Typhimurium were resistant to ampicillin and cephalotin yet no beta-lactamase (bla) genes were detected. In addition, $S$. Wien isolated from sheep was resistant to tetracycline but no tet $A$ nor tet $B$ genes were detected. Conversely, $S$. Chagoua, $S$. Essen, and $S$. Wien possessed the resistance genes but resistance phenotype was not observed. Similar observation was made by Afzal et al. [43] who reported $S$. Typhi isolates that were resistant to ampicillin and tetracycline with no detected corresponding 
resistance genes. In the opinion of previous study of Adesiji et al. [44], such phenomenon may be due to non-expression of the genes responsible referred to as silent gene. qnr genes that indicates plasmid-mediated resistance of quinolones and fluoroquinolones were detected. Among antibiotic-resistant serovars, 43\% were positive for $q n r B$ gene with only one $S$. Dabou having $q n r S$ in addition to $q n r B$; however, this isolate did not exhibit any phenotypic resistance to nalidixic acid nor ciprofloxacin. In a previous study, Fashae and Hendriksen [45] reported the detection of qnrB19 in $S$. Corvallis and qnrS1 in $S$. Derby isolated from pig farms in Ibadan, Nigeria. In this study, presumed mutations in gyrA gene would have resulted in ciprofloxacin resistance exhibited by serovars in which qnr genes were not detected, since mutation in gyr $A$ gene resulting in ciprofloxacin resistance is widespread in Africa [46]. According to Baker et al. [47], selective and sustained pressure is the driving force for the evolution of antimicrobial resistance. Evolutionary analysis of gyrA genes in this study showed that gyrA gene in $S$. enterica from both human and food animals exhibits variations but are evolutionarily interconnected. Three major clades and a single largely diverged lineage were observed from the phylogenetic relationship analysis of isolates from both human and food animals using sequences of gyrA genes. The major clade had five Salmonella serovars from human (S. Paratyphi C) and chicken ( $S$. Budapest and $S$. Agodi) clustering with X789771.1 $S$. Typhimurium serovar from the GenBank (NCBI), which was isolated from infected human subjects in the United Kingdom with a presumed zoonotic source: including chicken, turkey, eggs litter and imported exotic birds [48]. The second clade comprised $S$. Essen (g28) from chicken, $S$. Essen (g38) from sheep, and $S$. Tennyson (g21) from chicken, which was close to reference strain EU512997.1 S. Typhimurium from the GenBank, which was isolated from patients in Korea. Hence, a clonal expansion has been indicated by Chattaway et al. [49] who reported the difficulty in discerning clonal origin and distinguishing clonal expansion from evolutionary convergence of clonal lineages of fluoroquinolone-resistant $S$. Typhimurium DT104 and $S$. Kentucky. In this study, all bla $a_{T E M}$ genes detected were from isolates of sheep origin and belong to the TEM-144, TEM-135, and TEM-4 variants. This points to the fact that contaminated mutton could also be a potential source of betalactamase genes. Little or no attention has been paid to this food animal in terms of being a reservoir of antibiotic-resistant Salmonella serovars even when largely consumed in Nigeria. In this study, there was no resistance to third and fourth generation cephalosporins; however, utmost caution should be observed since dependency on this group of antibiotics in treatment most especially of children is high [37]. Thus, the need for prudent use of these drugs in both veterinary and human medicine is advocated to prevent the development of resistance. 
Food-borne Salmonella serovars remains a public health risk; hence, there is a need for continuous antimicrobial resistance surveillance and monitoring in food animals and humans. Antibiotic surveillance systems is generally lacking in Africa. Thus, the results from this study can serve as a template for broader and further studies to provide a comprehensive data that can be used for formulating policies for antibiotics regulation in human and animal medicine to prevent and control outbreaks of multidrug resistance in food animals and humans.

\section{Acknowledgements}

To the authors would like to express their profound gratitude to the International Center for Genetic Engineering and Biotechnology (ICGEB) for supporting this study through ICGEB-SMART Fellowship (Fellowship number: S/NGA 16-02), National Food Institute (DTU Food) Denmark for providing all the reference strains used as positive controls, Prof. M. Dosso of Institute Pasteur Cote d'Ivoire for providing a research space for this work, and Mr. Perri Ehue and Mr. A. Sylla for their contributions to the success of this work.

\section{Ethical approval}

Ethical approval for this study was obtained from the Human Research and Ethical Committee (HREC) of the Lagos University Teaching Hospital with code number ADM/DCST/HREC/APP/1118 and Nigerian Institute of Medical Research Institutional Review Board, with project number IRB/12/180.

\section{Conflict of Interest}

The authors declare no conflict interest.

\section{References}

1. Crump, J. A., Sjolund-Karlsson, M., Gordon, M. A., Parry, C. M.: Epidemiology, clinical presentation, laboratory diagnosis, antimicrobial resistance and antimicrobial management of invasive Salmonella infections. Clin Microbiol Rev 28, 901-937 (2015).

2. Freitas, N. O. C., Penha, F. R. A. C., Barrow, P., Berchier, J. A.: Source of human nontyphoidal salmonellosis: A review. Braz J Poultry Sci 12, 1-11 (2010). 
3. Mellon, G., Delanoe, C., Roux, A. L., Heym, B., Dubourg, O., Hardy, P., Chevallier, B., Perronne, C., Rouveix, E., Salomon, J.: Non-typhi Salmonella enterica urinary tract infection. Med Mal Infect 47, 389-393.

4. Marks, F., von Kalckrevth, V., Aaby, P., Adu-Sarkodie, Y., El-Tayeb, M. A., Ali, M., Aseffa, A., Baker, S., Biggs, H. M., Bjerregaard-Andersen, M., Breiman, R. F., Campbell, J. I., Cosmas, L., Crump, J. A., Espinoza, L. M., Deerin, J. F., Dekker, D. M., Fields, B. S., Gasmelseed, N., Hertz, J. T., Van Minh Hoang, N., Im, J., Jaeger, A., Jeon, H. J., Kabore, L. P., Keddy, K. H., Konings, F., Krumkamp, R., Ley, B., Løfberg, S. V., May, J., Meyer, C. G., Mintz, E. D., Montgomery, J. M., Niang, A. A., Nichols, C., Olack, B., Pak, G. D., Panzner, U., Park, J. K., Park, S. E., Rabezanahary, H., Rakotozandrindrainy, R., Raminosoa, T. M., Razafindrabe, T. J., Sampo, E., Schütt-Gerowitt, H., Sow, A. G., Sarpong, N., Seo, H. J., Sooka, A., Soura, A. B., Tall, A., Teferi, M., Thriemer, K., Warren, M. R., Yeshitela, B., Clemens, J. D., Wierzba, T. F.: Incidence of invasive Salmonella disease in Sub-Saharan Africa: A multicenter population based surveillance study. Lancet Glob Health 5, e310-323 (2017).

5. Deekshit, V. K., Kumar, B. K., Rai, P., Rohit, A., Karunasagar, I.: Simultaneous detection of Salmonella pathogenicity island 2 and its antibiotic resistance genes from seafood. J Microbiol Methods 93, 233-238 (2013).

6. Smith, S., Branu, S., Akintimehin, F., Fesobi, T., Bamidele, M., Coker, A., Monecke, S., Ehricht, R.: Serogenotyping and antimicrobial susceptibility testing of Salmonella spp. isolated from retail meat samples in Lagos, Nigeria. Mol Cell Probe 30, 189-194 (2016).

7. Kjeldsen, M. K., Torpdah, I. M., Campos, J., Pedersen, K., Nielsen, E. M.: Multiple locus variable number tandem repeat analysis of Salmonella enterica subsp. enterica serovar Dublin. J Appl Microbiol 116, 1044-1054 (2014).

8. Raufu, I. A., Lawan, F. A., Bello, H. S., Musa, A. S., Ameh, J. A., Ambali, A. G.: Occurrence and antimicrobial susceptibility profiles of Salmonella serovars from fish in Maiduguri Sub-Saharan Nigeria. Egypt J Aquat Res 40, 59-63 (2014).

9. Niemann, J., Tietze, E., Ruddat, I., Fruth, A., Prager, R., Rabsch, W., Blaha, T., Munchhausen, C., Merle, R., Kreienbrock, L.: Epidemiological analysis of the dynamic and diversity of Salmonella spp. in five German pig production clusters using phenol and genotyping methods: An exploratory study. Vet Microbiol 176, 190-195 (2015).

10. Aboud, O. A. A., Adaska, J. M., Williams, D. R., Rossitto, P. V., Champagne, J. D., Lehenbauer, T. W., Atwill, R., Li, X., Aly, S. S.: Epidemiology of Salmonella sp. in California cull dairy cattle: Prevalence of faecal shedding and diagnostic accuracy of pooled enriched broth culture of faecal samples. Peer J 4, e2386 (2016).

11. Fagbamila, I. O., Barco, L., Mancin, M., Kwaga, J., Ngulukun, S. S., Zavagnin, P.: Salmonella serovars and their distribution in Nigeria commercial chicken layer farms. PLoS One 12, e0173097 (2017).

12. Yue, M., Schifferli, D. M.: Allelic variation in Salmonella: An underappreciated driver of adaptation and virulence. Front Microbiol 4, 419 (2014).

13. World Health Organization. Antimicrobial Resistance. Global Report on Surveillance. Geneva, Switzerland: WHO Press, World Health Organization, 2014. Available at www.who.int

14. Abatcha, M. G., Zakaria, Z., Kaur, D. G., Thong, K. L.: Review article: A trend of Salmonella and antibiotic resistance. Adv Life Sci Technol 17, 9-21 (2014). 
15. Yi, L., Wang, J., Gao, Y., Liu, Y., Doi, Y., Wu, R., Zeng, Z., Liang, Z., Liu, J.-H.: MCr-1Harboring Salmonella enterica serovar Typhimurium sequence type 34 in pigs, China. Emerg Infect Dis 23, 291-295 (2017).

16. Djeffal, S., Bakour, S., Mamache, B., Elgroud, R., Agabou, A., Chabou, S., Hireche, S., Bouaziz, O., Rahal, K., Rolain, J. M.: Prevalence and clonal relationship of ESBLproducing Salmonella strains from humans and poultry in Northeastern Algeria. BMC Vet Res 13, 132 (2017).

17. Fashae, K., Ogunsola, F., Aarestrup, F. M., Hendriksen, R. S.: Antimicrobial susceptibility and serovars of Salmonella from chicken and humans in Ibadan, Nigeria. J Infect Dev Ctries 4, 484-494 (2010).

18. Smith, S. I., Fowora, M. A., Goodluck, H. A., Nwaokorie, F. O., Aboaba, O. O., Opere, B.: Molecular typing of Salmonella spp. isolated from food handlers and animals in Nigeria. Int J Mol Epidemiol Genet 2, 73-77 (2011).

19. Agada, G. O. A., Abdullahi, I. O., Aminu, M., Odugbo, M., Chollom, S. C., Kumbish, P. R., Okwori, A. E. J.: Prevalence and antibiotic resistance profile of Salmonella isolates from commercial poultry and poultry farm-handlers in Jos, Plateau state Nigeria. $\mathrm{Br}$ Microbiol Res J 4, 462-479 (2014).

20. Smith, S. I., Fowora, M. A., Tiba, A., Anejo-Okopi, J., Fingesi, T., Adamu, M. E., Omonigbehin, E. A., Ugo-IJeh, M. I., Bamidele, M., Odeigah, P.: Molecular detection of some virulence genes in Salmonella spp. isolated from food samples in Lagos, Nigeria. Anim Vet Sci 3, 22-27 (2015).

21. Grimont, P. A. D., Weill, F. X.: Antigenic Formulae of the Salmonella Serovas, $9^{\text {th }}$ Edition. World Health Organization Collaborating Center for Reference and Research on Salmonella Institute Pasteur, Paris, France, 2007.

22. The European Committee on Antimicrobial Susceptibility Testing (EUCAST): Break Point Tables for Interpretation of MICs and Zone Diameters Version 1.0, 2016. Available at http://www.eucast.org (Accessed 16 April 2017).

23. Adi, P. J., Naidu, J. R., Matcha, B.: Multiplex quantification of Escherichia coli, Salmonella typhi and Vibrio cholera with three DNA targets in single reaction assay. Microb Pathog 110, 50-55 (2017).

24. Cavaco, L. M., Frimodt-Moller, N., Hasman, H., Guardabassi, L., Nielsen, L., Aarestrup, F. M.: Prevalence of quinolone resistance mechanisms and associations to minimum inhibitory concentrations in quinolone-resistant Escherichia coli isolated from humans and swine in Denmark. Microb Drug Resist 14, 163-169 (2008).

25. Cattoir, V., Weill, F. X., Poirel, L., Fabre, L., Soussy, C. J., Nordmann, P.: Prevalence of $q n r$ genes in Salmonella in France. J Antimicrob Chemother 59, 751-754 (2007).

26. Wiuff, C., Madsen, M., Baggesen, D. L., Aarestrup, F. M.: Quinolone resistance among Salmonella enterica from cattle broilers, and swine in Denmark. Microb Drug Resist 6, 11-17 (2000).

27. Olesen, I., Hasman, H., Aarestrup, F. M.: Prevalence of beta-lactamases among ampicillinresistant Escherichia coli and Salmonella isolated from food animals in Denmark. Microb Drug Resist 10, 334-340 (2004).

28. Hendriksen, R. S., Mikoleit, M., Kornschober, C., Rickert, R. L., Duyne, S. V., Kjelso, C., Hasman, H., Cormican, M., Mevius, D., Threlfall, J., Angulo, F. J., Aarestrup, F. M.: Emergence of multidrug resistant Salmonella Concord infection in Europe and the United States in children adopted from Ethiopia 2003-2007. Pediatr Infect Dis J 28, 814-818 (2009). 
29. Arlet, G., Rouveau, M., Philippon, A.: Substitution of alanine for aspartate at position 197 in the SHV-6 extended spectrum beta-lactamase. FEMS Microbiol Lett 152, 163-167 (2007).

30. Waters, S. H., Rogowsky, P., Grinsted, J., Altenbuchner, J., Schmitt, R.: The tetracycline resistance determinants of RP1 and Tn1721: nucleotide sequence analysis. Nucleic Acids Res 11, 6089-6105 (1983).

31. Sengelov, G., Agerso, Y., Halling-Sorensen, B., Baloda, S. B., Andersen, J. S., Jensen, L. B.: Bacterial antibiotic resistance levels in Danish farmland as a result of treatment with pig manure slurry. Environ Int 28, 587-595 (2003).

32. Kumar, S., Stecher, G., Tamura, K.: MEGA 7: Molecular Evolutionary Genetic Analysis version 7.0 for bigger datasets. Mol Biol Evol 33, 1870-1874 (2016).

33. Raufu, I., Hendriksen, R. S., Ameh, J. A., Aarestrup, F. M.: Occurrence and characterization of Salmonella Hiduddify from chicken and poultry meat in Nigeria. Foodborne Pathog Dis 6, 425-430 (2009).

34. Centers for Disease Control and Prevention (CDC): National Salmonella Surveillance Annual Report, 2013. Atlanta, Georgia: US Department of Health and Human Services, CDC, 2016. Available at www.cdc.gov/nationalsurveillance/Salmonella-surveillance. html.Accessed on: September 20, 2017).

35. Morpeth, S. C., Ramadhani, H. O., Crump, J. A.: Invasive non-Typhi Salmonella disease in Africa. Clin Infect Dis 49, 606-611 (2009).

36. Mezal, E. H., Stefanova, R., Khan, A. A.: Isolation and molecular characterization of Salmonella enterica serovar Javiana from food, environment and clinical samples. Int $\mathbf{J}$ Food Microbiol 164, 113-118 (2013).

37. Medalla, F., Gu, W., Mahon, B. E., Judd, M., Folster, J., Griffin, P. M., Hoekstra, R. M.: Estimated incidence of antimicrobial drug-resistant nontyphoidal Salmonella infections, United States, 2004-2012. Emerg Infect Dis 23, 29-37 (2017).

38. Boqvist, B. S., Hansson, I., Bjerselius, U. N., Hamilton, C., Wahlstrom, H., Noll, B., Tysen, E., Engvau, A.: Salmonella isolated from animals and feed production in Sweden between 1993-1997. Acta Vet Scand 44, 181-197 (2003).

39. Trongjit, S., Angkititrakul, S., Tuttle, R. E., Poungseree, J., Padungtod, P., Chuanchuen, R.: Prevalence and antimicrobial resistance in Salmonella enterica isolated from broiler chicken, pigs and meat products in Thailand-Cambodia border provinces. Microbiol Immunol 61, 23-33 (2017).

40. Wen, S. C. H., Best, E., Nourse, C.: Non-typhoidal Salmonella infections in children: Review of literature and recommendations for management. J Paediatr Child Health 53, 936-941 (2017).

41. Raufu, I., Bortolaia, V., Svendsen, C. A., Ameh, J. A., Ambali, A. G., Aarestrup, F. M., Hendriksen, R. S.: The first attempt of an active integrated laboratory based Salmonella surveillance programme in the north-eastern region of Nigeria. J Appl Microbiol 115, 1059-1067 (2013).

42. Zhu, Y., Lai, H., Zou, L., Yin, S., Wang, C., Han, X., Xia, X., Hu, K., He, L., Zhou, K., Chen, S., Ao, X., Liu, S.: Antimicrobial resistance and resistance genes in Salmonella strains isolated from broiler chickens along the slaughtering process in China. Int J Food Microbiol 259, 43-51 (2017). 
43. Afzal, A., Sarwar, Y., Ali, A., Maqbool, A., Salman, M., Habeeb, M. A., Haque, A.: Molecular evaluation of drug resistance in clinical isolates of Salmonella enterica serovar Typhi from Pakistan. J Infect Dev Ctries 7, 929-940 (2013).

44. Adesiji, Y. O., Deekshit, V. K., Karunasagar, I.: Antimicrobial-resistant genes associated with Salmonella spp. isolated from human, poultry and seafood sources. Food Nutr $\mathbf{2}$, 436-442 (2014).

45. Fashae, K., Hendriksen, R. S.: Diversity and antimicrobial susceptibility of Salmonella enterica serovars isolated from pig farms in Ibadan, Nigeria. Folia Microbiol 59, 69-77 (2013).

46. Tadesse, G., Tessema, T. S., Beyene, G., Aseffa, A.: Molecular epidemiology of fluoroquinolone resistant Salmonella in Africa: A systematic review and meta-analysis. PLoS ONE 13, e0192575 (2018).

47. Baker, S., Duy, P. T., Nga, T. V. T., Dung, T. T. N., Phat, V. V., Chau, T. T., Turner, A. K., Farrar, J., Boni, M. F.: Fitness benefits in fluoroquinolone resistant Salmonella Typhi in the absence of antimicrobial pressure. eLife 2, e01229 (2013).

48. Griggs, D. J., Gensberg, K., Piddock, L. J. V.: Mutations in gyrA gene of quinolone resistant Salmonella serotypes isolated from humans and animals. Antimicrob Agents Chemother 40, 1009-1013 (1996).

49. Chattaway, M. A., Aboderin, A. O., Fashae, K., Okoro, C. K., Opintan, J. A., Okeke, I. N.: Fluoroquinolone-resistant enteric bacteria in sub-Saharan Africa: Clones, implications and research needs. Front Microbiol 7, 558 (2016). 